\title{
Prognostic role of epidermal growth factor receptor mutation status in patients with de novo lung adenocarcinoma
}

\author{
Bo Li ${ }^{1 \#}$, Xiaolu Ren ${ }^{1 \#}$, Hongxia Guo ${ }^{2}$, Yi Guo ${ }^{3}$, Fei Han ${ }^{4}$, Xiaolian Wen ${ }^{5}$, Jing Wu ${ }^{1}$, Xiaomin $\mathrm{Li}^{1}$, \\ Yuejun Ren $^{1}$, Xiaoyun $\mathrm{Hu}^{6}$, Zhihong Liu, \\ ${ }^{1}$ Department of Radiation Oncology, Shanxi Cancer Hospital, Taiyuan, China; ${ }^{2}$ Department of Oncology, Shanxi Bethune Hospital, Taiyuan, China; \\ ${ }^{3}$ Department of Respiration, Shanxi Cancer Hospital, Taiyuan, China; ${ }^{4}$ Department of Thoracic Surgery, Shanxi Cancer Hospital, Taiyuan, China; \\ ${ }^{5}$ Department of Hematology, Shanxi Cancer Hospital, Taiyuan, China; ${ }^{6}$ Department of Respiration, First Hospital of Shanxi Medical University, \\ Taiyuan, China; ${ }^{7}$ Shanxi Medical University, Taiyuan, China \\ Contributions: (I) Conception and design: B Li, X Ren, Z Liu; (II) Administrative support: J Wu, X Li, Y Ren; (III) Provision of study materials or \\ patients: B Li, H Guo; (IV) Collection and assembly of data: B Li, H Guo, Y Guo, F Han; (V) Data analysis and interpretation: X Ren, X Hu, X \\ Wen, Z Liu; (VI) Manuscript writing: All authors; (VII) Final approval of manuscript: All authors. \\ \#These authors contributed equally to this work. \\ Correspondence to: Zhihong Liu. First Hospital of Shanxi Medical University, 56th Xinjian South Road, Taiyuan 030001, China. Email: liuzhdoc@163.com.
}

Background: To explore the relationship between the status of epidermal growth factor receptor (EGFR) and overall survival (OS) in de novo lung adenocarcinoma.

Methods: We retrospectively analyzed 291 lung adenocarcinoma subjects with exact EGFR status. The cases were divided into a mutant-type group (124 patients) and wild-type group (167 patients) according to the status of EGFR. The general information, OS, and possible risk factors influencing the OS were also evaluated.

Results: The EGFR mutation rate was 42.6\% (124/291 patients), and there were statistically significant differences in gender, smoking history, and OS $(\mathrm{P}<0.05)$, but no significant difference in diagnosed age, alcohol history, TNM stage, clinical stage, and immunohistochemistry between the two groups $(\mathrm{P}>0.05)$. The most common subtypes of EGFR mutations were exon 19 and exon 21. The median OS of the total population was 30.20 months [95\% confidence interval (CI): 25.94-34.46 months] and the OS in the mutanttype group was better than in the wild-type group $(\mathrm{P}<0.001)$. Cox regression demonstrated that $\mathrm{N}$ stage, $\mathrm{M}$ stage, and EGFR status were the risk factors for OS in de novo lung adenocarcinoma patients $(\mathrm{P}<0.001)$, and the relative risk were 1.398 (95\% CI: 1.214-1.609), 2.427 (95\% CI: 1.780-3.310), and 2.030 (95\% CI: 1.528-2.699), respectively.

Conclusions: The OS of EGFR mutant individuals was better than that of wild-type patients in de novo lung adenocarcinoma patients. EGFR mutation may be a useful prognostic indicator in lung adenocarcinoma.

Keywords: Lung adenocarcinoma; epidermal growth factor receptor (EGFR); overall survival (OS)

Submitted Jan 27, 2021. Accepted for publication Mar 17, 2021.

doi: $10.21037 /$ tcr-21-402

View this article at: http://dx.doi.org/10.21037/tcr-21-402

\section{Introduction}

Lung cancer is the most common malignant tumor with high morbidity and mortality worldwide $(1,2)$. Lung adenocarcinoma is the most frequent pathological type of non-small cell lung cancer (NSCLC) and carries a poor prognosis (3). Epidermal growth factor receptor (EGFR) is a glycoprotein belonging to the ErbB family and has been shown to play an important role in tumorigenesis $(4,5)$. EGFR mutations are mainly found in patients with lung adenocarcinoma and several clinical trials (6-8) have 
confirmed that the application of EGFR tyrosine kinase inhibitors (TKIs) improves the prognosis of patients with positive EGFR mutations. Thus, EGFR-TKIs have been approved as a first-line therapeutic method for metastatic NSCLC with EGFR mutation (9). The advent of novel targeted therapies provides options for treatment strategies. However, there are few studies on the relationship between overall survival (OS) and the status of EGFR outside clinical trials. Therefore, 291 lung adenocarcinomas with known exact status of EGFR were retrospectively analyzed. The relationship between the status of EGFR and general clinical characteristics was explored in de novo lung adenocarcinoma and further investigation on the outcomes and the status of EGFR was also performed.

We present the following article in accordance with the REMARK reporting checklist (available at http://dx.doi. org/10.21037/tcr-21-402).

\section{Methods}

\section{Patients and clinical information}

The clinical details of 291 patients with primary lung adenocarcinoma diagnosed between January 2011 and December 2013 at the Shanxi Cancer Hospital were collected. The study was approved by the Ethics Committee of the Shanxi Cancer Hospital (ethical ID: 201835). All procedures performed in studies involving human participants followed the ethical standards of the institutional research committee of Shanxi Cancer hospital (Ethical ID: 201835) and the Helsinki declaration (as revised in 2013). Formal consent was not required for this retrospective study and the study did not involve animal experiments.

All patients were diagnosed as primary lung adenocarcinoma by either cytopathology or histopathology and EGFR status was confirmed. Patients with an unknown EGFR status or with mixed pathological types were excluded. Follow-up was provided by the Medical Records Department of our hospital. All cases were divided into a mutant-type group and wild-type group according to their EGFR status and the definition of metastatic status and TNM stage were based on the IASLC 8th TNM Lung Cancer Staging System. Initially, 337 cases were identified, and of these, 291 patients were ultimately selected. In addition, 396 individuals were excluded for the following reasons: (I) 23 patients had been treated before their EGFR status was determined; (II) 12 cases had a history of another malignancy or mixed pathological types; (II) three cases had incomplete laboratory data; and (IV) eight individuals had incomplete follow-up data.

\section{Detection of EGFR}

DNA extraction procedures of tissue specimens were performed as follows. Paraffin-embedded wax blocks were cut into four slices with $7 \mu \mathrm{m}$ thickness, then after dewaxing, benzol removal, and dyeing, the slices were placed into an Eppendorf tube. DNA was extracted according to the experimental steps of the QIAamp DNA FFPE Kit (Qiagen Company, Germany), then the concentration of DNA was adjusted to $20-30 \mathrm{ng} / \mu \mathrm{L}$ and stored at $-20^{\circ} \mathrm{C}$ to reserve.

The DNA extraction procedures of cytological specimens were as follows: Samples of lung adenocarcinoma patients scraped cancer cells were placed into an Eppendorf tube, and the number of cancer cells was not less than 200. DNA was extracted according to the instructions of the DNA extraction kit (Xiamen amoydx Technology Co., Ltd.) and stored at $-20^{\circ} \mathrm{C}$ to reserve.

\section{Detection of EGFR gene mutation}

The primers for polymerase chain reaction (PCR) amplification and sequencing were designed by AstraZeneca (Shanghai R\&D Center) and synthesized by the Shanghai Biological Company. Mutations in exons 18-21 of the EGFR gene were detected by amplification refractory mutation system (ARMs) and all experimental steps were completed according to the instructions of the $\mathrm{ADx}$-EGFR detection kit.

\section{Survival time}

All subjects were followed up by telephone and follow-up records and the end point was death or the last follow-up date. The survival time of the dead patients was defined as the date from diagnosis to death or last follow-up and the survival time was calculated in monthly units.

\section{Statistical analysis}

All data were analyzed using SPSS 22.0 for Windows (IBM, Armonk, NY, USA). Continuous data were presented as means \pm standard deviation and were analyzed using the Student $t$ test and categorical data were analyzed using the chi-square test or Fisher's exact test. Statistically significant 
differences were defined as two-sided $\mathrm{P}$ values $<0.05$. LogRank test was used to assess the survival time and Cox regression was used to analyze the prognostic factors. Variables with $\mathrm{P}<0.05$ in the Log-Rank test were analyzed by Cox regression.

\section{Results}

\section{Basic information between the two groups}

General information regarding the two groups is summarized in Table 1. Among involved patients, 124 had the EGFR mutation, 167 had wild-type EGFRe, and the mutation rate was $42.6 \%(124 / 291)$. The gender ratio was 146 males and 145 females, the median age was 58 years old, 121 cases were smokers, and 170 cases were nonsmokers. Distant metastases at the initial diagnosis were present in 147 cases, 95 cases underwent surgical resection at the initial treatment, and 11 cases underwent initial treatment after neoadjuvant chemotherapy. Radiotherapy and chemotherapy were provided in 133 cases, 13 cases used TKIs, and 39 cases received best supportive treatment. The 1-, 2-, 3-, and 5-year survival rates were $75.9 \%$,

Table 1 Basic information between the two groups

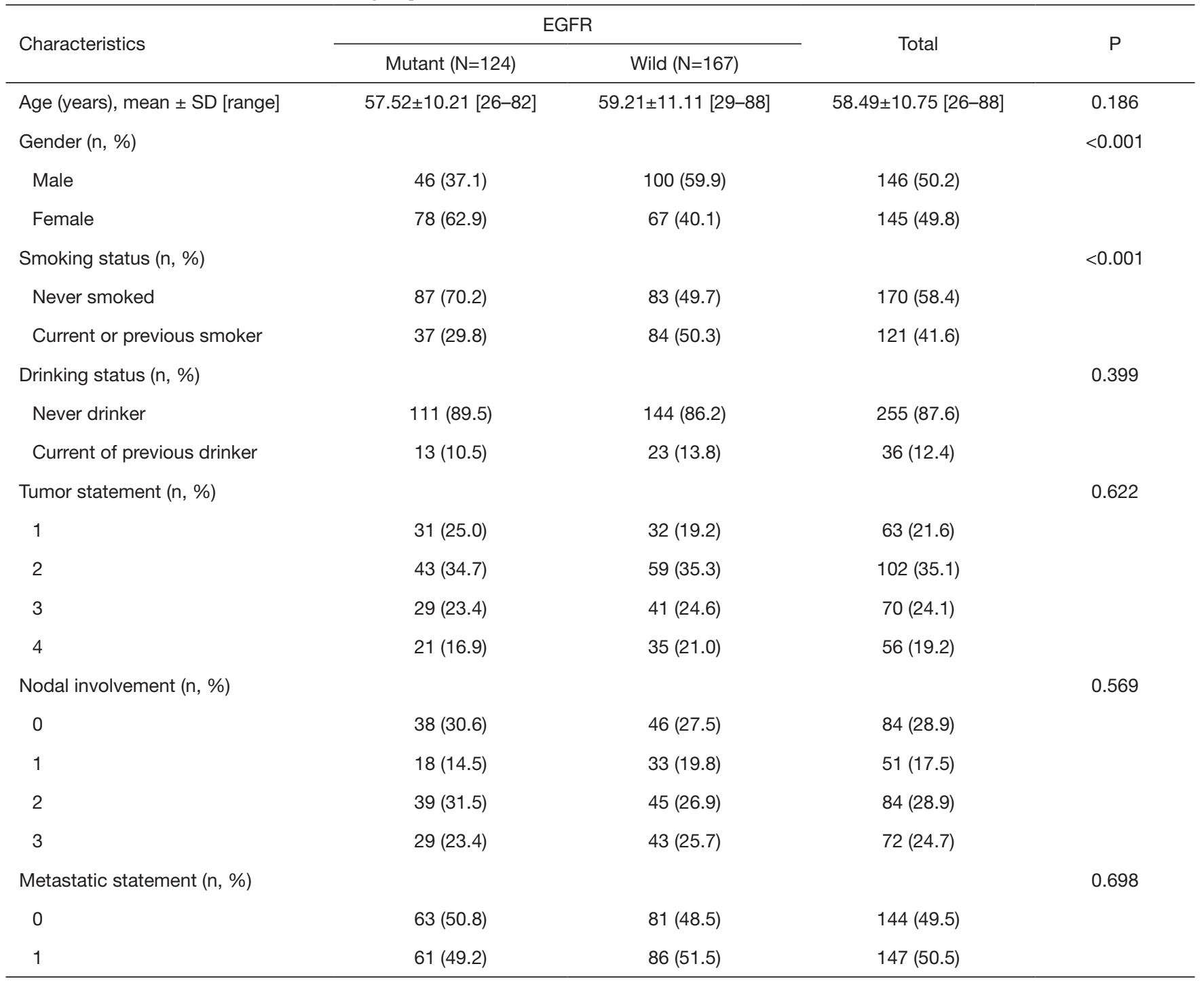

Table 1 (continued) 
Table 1 (continued)

\begin{tabular}{|c|c|c|c|c|}
\hline Characteristics & \multicolumn{2}{|c|}{ EGFR } & Total & $\mathrm{P}$ \\
\hline Stage (n, \%) & & & & 0.550 \\
\hline I & $22(17.7)$ & $20(12.0)$ & $42(14.4)$ & \\
\hline II & $15(12.1)$ & $20(12.0)$ & $35(12.0)$ & \\
\hline TTF-1 (n, \%) & & & & 0.048 \\
\hline Negative & $0(0)$ & $8(12.3)$ & $8(8.1)$ & \\
\hline Positive & $34(100.0)$ & $57(87.7)$ & 91 (91.9) & \\
\hline CK7 (n, \%) & & & & 0.526 \\
\hline Negative & $0(0)$ & $2(13.3)$ & $2(8.7)$ & \\
\hline Positive & $8(100.0)$ & $13(86.7)$ & 21 (91.3) & \\
\hline Ki67 score, mean \pm SD & $43.35 \pm 21.13$ & $35.97 \pm 19.43$ & $10.81 \pm 20.75$ & 0.109 \\
\hline Survival (n, \%) & & & & $<0.001$ \\
\hline Yes & $48(39.0)$ & $33(20.1)$ & $81(28.2)$ & \\
\hline No & $75(61.0)$ & 131 (79.9) & 206 (71.8) & \\
\hline Survival time (n, \%) & & & & $<0.001$ \\
\hline \multicolumn{5}{|l|}{ Survival rate $(\%)$} \\
\hline 1-year & 86.3 & 68.3 & 75.9 & 0.024 \\
\hline 2-year & 71.8 & 44.9 & 56.3 & 0.387 \\
\hline 3-year & 52.4 & 34.1 & 41.9 & 0.254 \\
\hline 5-year & 21.0 & 10.2 & 14.8 & 0.770 \\
\hline \multicolumn{5}{|l|}{ EGFR mutations (n, \%) } \\
\hline Exon 18 & $7(5.6)$ & & & \\
\hline Exon 19 & $56(45.2)$ & & & \\
\hline Exon 20 & $4(3.2)$ & & & \\
\hline Exon 21 & $52(41.9)$ & & & \\
\hline Exon 18 and 20 & $4(3.2)$ & & & \\
\hline Exon 18 and 21 & $1(0.8)$ & & & \\
\hline
\end{tabular}

EGFR, epidermal growth factor receptor. 
$56.3 \%, 41.9 \%$, and $14.8 \%$, respectively, and 42, 35, 67, and 147 cases had stage I, stage II, stage III and stage IV, respectively. KRAS was detected in 93 patients, including nine mutations and 84 non-mutations.

There were no significant differences in age, drinking exposure, TNM stages, clinical stages, and immunohistochemical results between mutant-type and wild-type patients $(\mathrm{P}>0.05)$. The EGFR mutation was more common in females and non-smokers $(\mathrm{P}<0.001)$, and showed a survival time of between 37 and 60 months, while the survival time of patients with the EGFR wild-type was less than 12 months $(\mathrm{P}<0.001)$. By the end of follow-up, among the 81 surviving patients, 48 were mutant-type and 33 were wild-type. The 1-, 2-, 3- and 5-year survival rates of mutant-type patients were $86.3 \%, 71.8 \%, 52.4 \%$, and $21.0 \%$, respectively and the 1-, 2-, 3- and 5-year survival rates of wild-type patients were $68.3 \%, 44.9 \%, 34.1 \%$, and $10.2 \%$, respectively.

\section{The subtypes of EGFR mutations}

Exon 19 mutations were the most common, accounting for $45.2 \%$ of all mutations, followed by 21 exon mutations, accounting for $41.9 \%$. Exon 18 mutations were detected in seven cases $(5.6 \%)$ and exon 20 mutations in four cases (3.2\%). There were four patients with exon 18 combined with exon 20 mutation $(3.2 \%)$, and one patient with exon 18 combined with exon 21 mutation $(0.8 \%)$. Simultaneous mutations in both EGFR and KRAS were not detected.

\section{OS between the two groups}

By the end of follow-up, 210 patients had died. The median OS was 30.20 months (95\% CI: 25.94-34.46 months), the median OS of mutant-type patients was 41.60 months (95\% CI: 27.51-55.69 months), and that of the wild-type patients was 19.87 months (95\% CI: 15.35-24.39 months), respectively. The OS of mutant-type patients was better than that of wild-type patients $(\mathrm{P}<0.001)$. The OS in global patients and wild-type patients was significantly correlated with TNM stages and clinical stages $(\mathrm{P}<0.001)$, yet the OS of mutant-type individuals was only associated with $\mathrm{N}$ and $M$ stages and clinical stages $(\mathrm{P}<0.001)$ and not with $\mathrm{T}$ stages $(\mathrm{P}=0.137)$ (Table 2). To further confirm the risk factors for OS, Cox regression was performed, which included TNM stages, clinical stages, and the status of EGFR. The results showed that $\mathrm{N}$ stage, $\mathrm{M}$ stage, and EGFR mutation were risk factors for $\mathrm{OS}(\mathrm{P}<0.001)$, and the relative risk was 1.398
(95\% CI: 1.214-1.609), 2.427 (95\% CI: 1.780-3.310), and 2.030 (95\% CI: 1.528-2.699), respectively (Figure 1).

\section{Discussion}

NSCLC is prone to be diagnosed in its advanced stages when the prognosis is poor (10). EGFR belongs to the ErbB family which has tyrosine kinase activity, and its abnormal function can lead to unusual cell proliferation, adhesion, and migration variation, which promotes the invasion and metastasis of cancer cells (11). Some studies showed EGFR mutation was more likely to respond to EGFRTKIs in lung adenocarcinomas patients and led to longer progression-free survival (PFS) $(12,13)$. In the present study, we observed the relationship between the status of EGFR and outcomes in lung adenocarcinomas. The rate of EGFR mutations has varied in previous studies and a higher rate has been found in Asians, females, and non-smokers (14), while in Europe, the rate of EGFR mutations was only $16.6 \%$ in Spain (7) and $4.9 \%$ in Germany (15).

Studies analyzing lung adenocarcinoma patients in areas of Southeast Asia (14) showed that the mutation frequency of EGFR varied from region to region. The mutant rate of the EGFR gene in China was $50.2 \%$, and the mutant rate in females $(61.1 \%)$ was higher than that of males $(44.0 \%)$, while age had no effect on the mutation of EGFR. The results of our study support these findings.

EGFR mutations are most common in lung adenocarcinomas and are associated with particular clinical features. Some researchers have analyzed the relationship between EGFR mutation and clinical and pathological features (16) and showed higher mutant rates were found in Asians, females, and non-smokers (17), which is consistent with our study. We retrospectively analyzed 291 lung adenocarcinomas with exact status of EGFR and the results showed that the mutant rate was $42.6 \%$, and OS of mutanttype patients was better than that of wild-type patients.

Some studies have found that exon 19 and exon 21 were more common in all EGFR mutations $(18,19)$, which is consistent with our research. However, while there was no difference in OS between exon 19 mutations and exon 21 mutations after gefitinib treatment (20), other studies have shown opposing results. The OS in patients with exon 19 deletion mutation was better than that with exon $21 \mathrm{~L} 858 \mathrm{R}$ mutation, and first-line treatment did not affect OS $(21,22)$. In contrast, in the present study, there was no difference in OS with each subtype of EGFR mutations. Fewer deaths occurred in the mutant-type group and the different clinical 


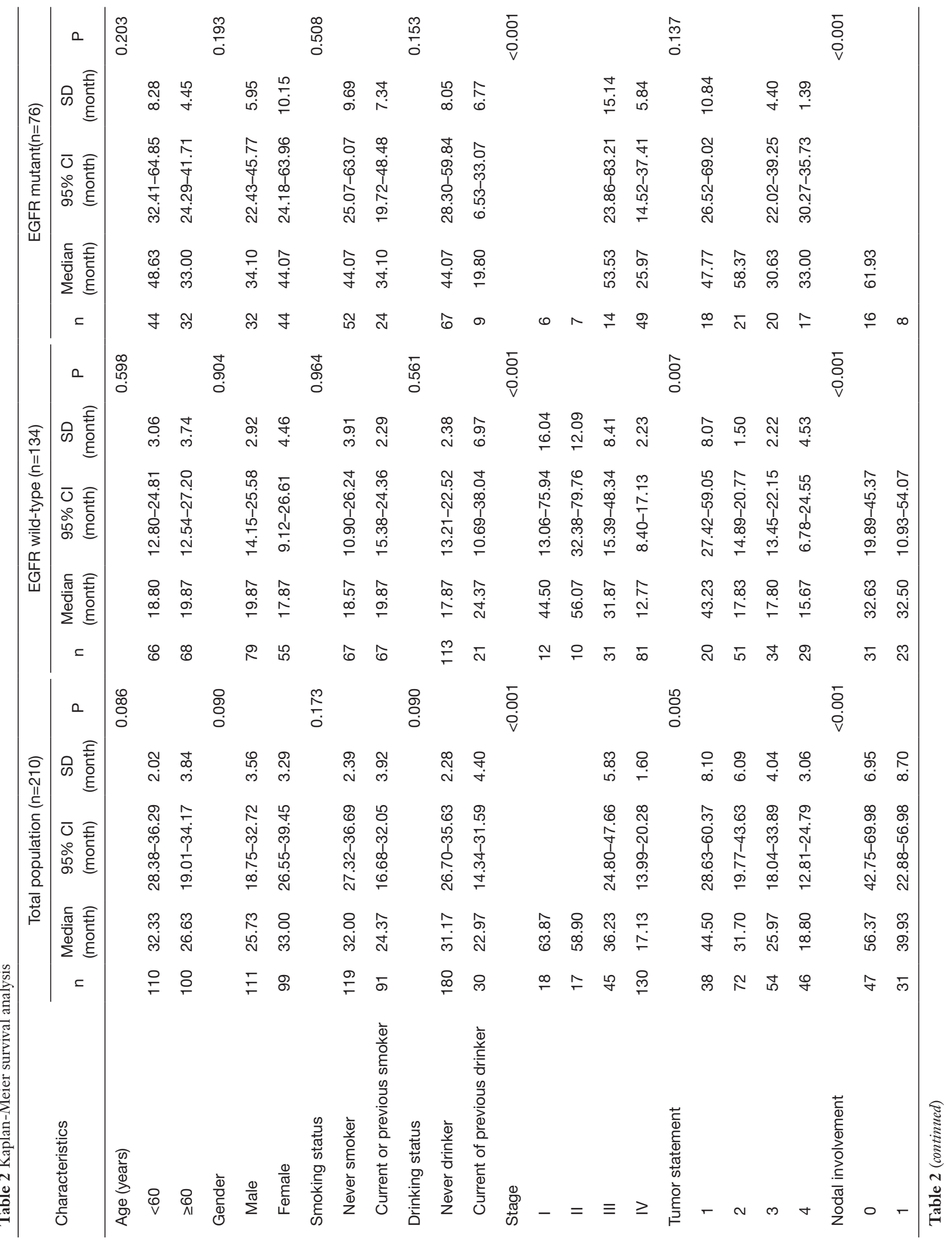




$$
\begin{aligned}
& \begin{array}{ll|ll}
a & \overline{0} & \multicolumn{1}{c}{} \\
& 0 & 0 & 0
\end{array}
\end{aligned}
$$

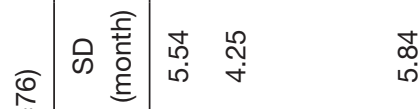

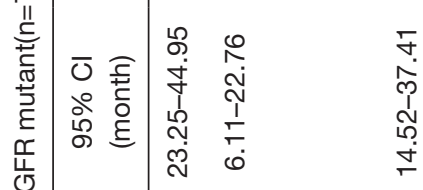

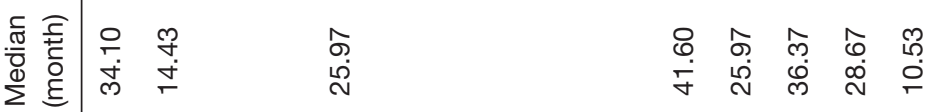

$$
\begin{aligned}
& =\stackrel{\sim}{\sim} \underset{\sim}{\sim} \quad \sim \quad \infty \\
& \therefore \quad \begin{array}{c}
\overline{8} \\
\dot{v}
\end{array}
\end{aligned}
$$

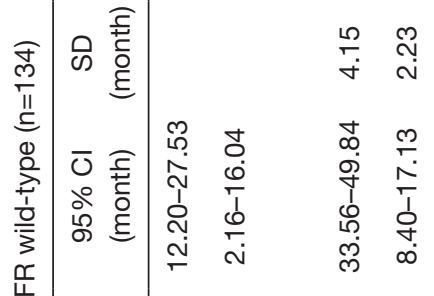

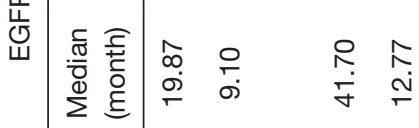

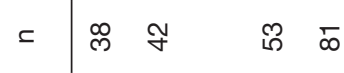

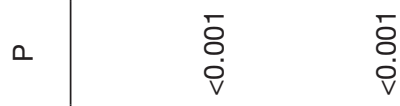

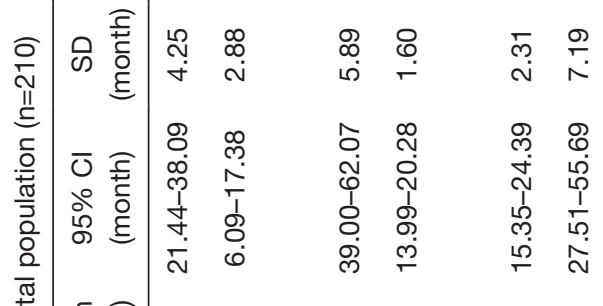

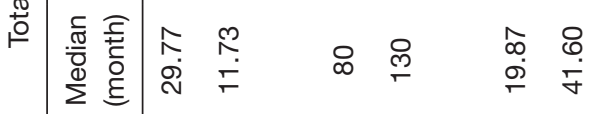

$$
\begin{aligned}
& =\begin{array}{llll}
\text { वे } & 0 & 0 & 0
\end{array}
\end{aligned}
$$

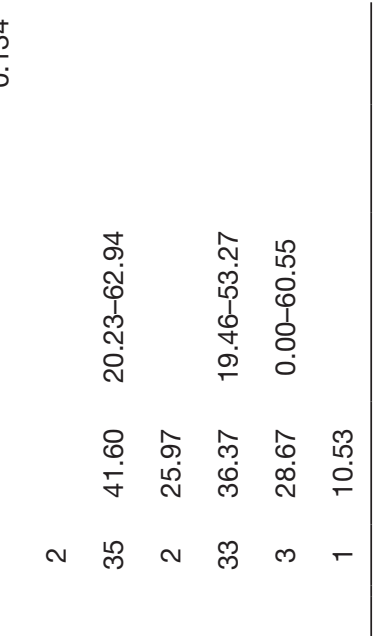

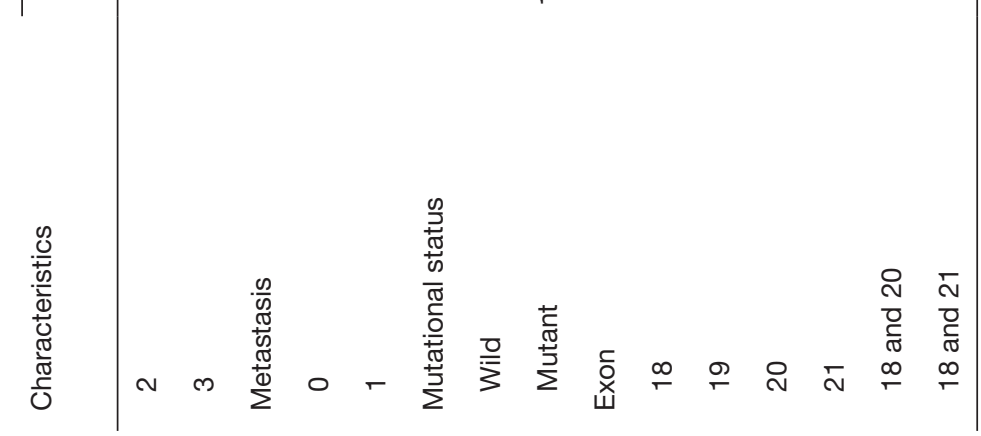




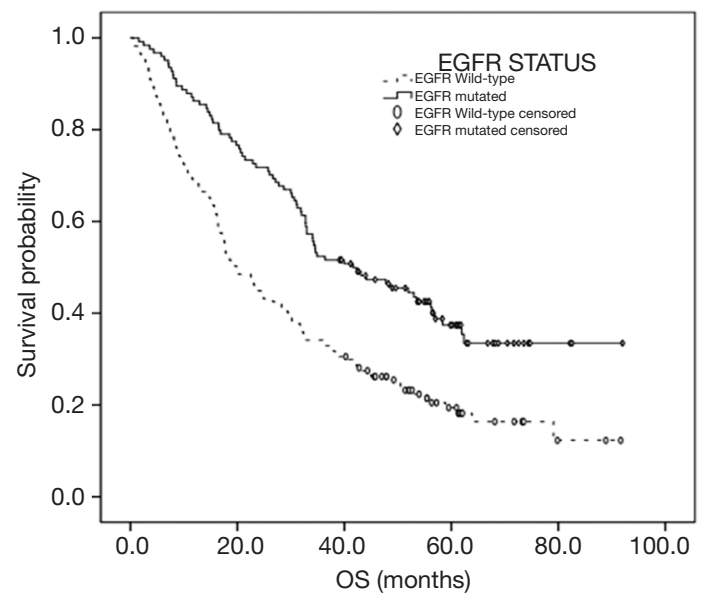

Figure 1 Kaplan-Meier Survival curve of EGFR mutated patients (continuous line) versus EGFR wild-type patients (dotted line). $\mathrm{P}$ value $<0.001$. EGFR, epidermal growth factor receptor.

treatments may have contributed to this. In the LUXLung6 clinical trial (23), OS in a mutant-type group was 9 months longer than that in a wild-type group. However, in a cross-sectional study of phase IV lung adenocarcinoma patients using second-generation sequencing (22), the OS of wild-type patients was better than that of mutanttype patients. In our study, the OS of both wild-type and mutant-type patients was slightly higher than that reported in clinical trials, although this disparity may be due to a loss of follow-up following premature death.

In addition, some studies (24) have revealed that the response to chemotherapy was better in EGFR mutant-type patients than that of wild-type patients, which may also lead to longer survivals. Some studies (25) demonstrated that there was no survival difference between EGFR mutations treated with TKIs and those which were not. However, patients with mutant-type usually choose surgery or radiotherapy and chemotherapy as first-line treatment, and if these treatments fail or the disease progresses, EGFRTKIs treatment can be used to prolong the OS of these patients. At the same time, with the wide application of TKIs and immunotherapy, there are more choices for a therapeutic strategy. Finally, the economic status and desire for treatment of patient's is also related to OS. Although most EGFR mutations occurred in non-smoking women with lung adenocarcinoma, there was still no difference in OS. In this study, $\mathrm{N}$ stage, $\mathrm{M}$ stage, clinical staging, and EGFR mutation were the risk factors of OS in lung adenocarcinomas.
There are some limitations to our study. Firstly, the nature of retrospective studies causes selection bias. In addition, specific treatment methods and other gene mutations were not included in this study. Finally, because of the heterogeneity of malignancy, multi-center studies using larger cohorts are required to confirm the results.

In conclusion, EGFR mutation is more likely to be detected in adenocarcinomas, females, and non-smokers. In addition to the clinical stage, EGFR mutation is a prognostic factor in lung adenocarcinoma.

\section{Acknowledgments}

Funding: This work was supported by the health commission of Shanxi Province (2020058).

\section{Footnote}

Reporting Checklist: The authors have completed the REMARK reporting checklist. Available at http://dx.doi. org/10.21037/tcr-21-402

Data Sharing Statement: Available at http://dx.doi. org/10.21037/tcr-21-402

Conflicts of Interest: All authors have completed the ICMJE uniform disclosure form (available at http://dx.doi. org/10.21037/tcr-21-402). The authors have no conflicts of interest to declare.

Ethical Statement: The authors are accountable for all aspects of the work in ensuring that questions related to the accuracy or integrity of any part of the work are appropriately investigated and resolved. The study was approved by the Ethics Committee of the Shanxi Cancer Hospital (ethical ID: 201835). All procedures performed in studies involving human participants followed the ethical standards of the institutional research committee of Shanxi Cancer hospital (Ethical ID: 201835) and the Helsinki declaration (as revised in 2013). Formal consent was not required for this retrospective study and the study did not involve animal experiments.

Open Access Statement: This is an Open Access article distributed in accordance with the Creative Commons Attribution-NonCommercial-NoDerivs 4.0 International License (CC BY-NC-ND 4.0), which permits the noncommercial replication and distribution of the article with 
the strict proviso that no changes or edits are made and the original work is properly cited (including links to both the formal publication through the relevant DOI and the license). See: https://creativecommons.org/licenses/by-nc-nd/4.0/.

\section{References}

1. Ferlay J, Soerjomataram I, Dikshit R, et al. Cancer incidence and mortality worldwide: sources, methods and major patterns in GLOBOCAN 2012. Int J Cancer 2015;136:E359-86.

2. Zheng R, Zeng H, Zuo T, et al. Lung cancer incidence and mortality in China, 2011. Thorac Cancer 2016;7:94-9.

3. Abernethy AP, Arunachalam A, Burke T, et al. Real-world first-line treatment and overall survival in non-small cell lung cancer without known EGFR mutations or ALK rearrangements in US community oncology setting. PLoS One 2017;12:e0178420.

4. Sharma SV, Bell DW, Settleman J, et al. Epidermal growth factor receptor mutations in lung cancer. Nat Rev Cancer 2007;7:169-81.

5. Steuer CE, Ramalingam SS. Targeting EGFR in lung cancer: lessons learned and future perspectives. Mol Aspects Med 2015;45:67-73.

6. Pao W, Miller V, Zakowski M, et al. EGF receptor gene mutations are common in lung cancers from 'never smokers' and are associated with sensitivity of tumors to gefitinib and erlotinib. Proc Natl Acad Sci U S A 2004;101:13306-11.

7. Rosell R, Moran T, Queralt C, et al. Screening for epidermal growth factor receptor mutations in lung cancer. N Engl J Med 2009;361:958-67.

8. Ninomiya T, Nogami N, Kozuki T, et al. A phase I trial of afatinib and bevacizumab in chemo-naïve patients with advanced non-small-cell lung cancer harboring EGFR mutations: Okayama Lung Cancer Study Group Trial 1404. Lung Cancer 2018;115:103-8.

9. Novello S, Barlesi F, Califano R, et al. Metastatic nonsmall-cell lung cancer: ESMO Clinical Practice Guidelines for diagnosis, treatment and follow-up. Ann Oncol 2016;27:v1-v27.

10. Franceschini JP, Jamnik S, Santoro IL. Survival in a cohort of patients with lung cancer: the role of age and gender in prognosis. J Bras Pneumol 2017;43:431-6.

11. Ellerbroek SM, Halbleib JM, Benavidez M, et al. Phosphatidylinositol 3-kinase activity in epidermal growth factor-stimulated matrix metalloproteinase-9 production and cell surface association. Cancer Res 2001;61:1855-61.
12. Wang $\mathrm{H}$, Zhang $\mathrm{M}$, Tang $\mathrm{W}$, et al. Mutation abundance affects the therapeutic efficacy of EGFR-TKI in patients with advanced lung adenocarcinoma: a retrospective analysis. Cancer Biol Ther 2018;19:687-94.

13. Lynch TJ, Bell DW, Sordella R, et al. Activating mutations in the epidermal growth factor receptor underlying responsiveness of non-small-cell lung cancer to gefitinib. N Engl J Med 2004;350:2129-39.

14. Shi Y, Au JS, Thongprasert S, et al. A prospective, molecular epidemiology study of EGFR mutations in Asian patients with advanced non-small-cell lung cancer of adenocarcinoma histology (PIONEER). J Thorac Oncol 2014;9:154-62

15. Boch C, Kollmeier J, Roth A, et al. The frequency of EGFR and KRAS mutations in non-small cell lung cancer (NSCLC): routine screening data for central Europe from a cohort study. BMJ Open 2013;3:e02560.

16. Sun PL, Seol H, Lee HJ, et al. High incidence of EGFR mutations in Korean men smokers with no intratumoral heterogeneity of lung adenocarcinomas: correlation with histologic subtypes, EGFR/ TTF-1 expressions, and clinical features. J Thorac Oncol 2012;7:323-30.

17. Aguiar F, Fernandes G, Queiroga H, et al. Overall Survival Analysis and Characterization of an EGFR Mutated NonSmall Cell Lung Cancer (NSCLC) Population. Arch. Bronconeumol 2018;54:10-7.

18. de Mello RA, Pires FS, Marques DS, et al. EGFR exon mutation distribution and outcome in non-small-cell lung cancer: a Portuguese retrospective study. Tumour Biol 2012;33:2061-8.

19. Skov BG, Høgdall E, Clementsen P, et al. The prevalence of EGFR mutations in non-small cell lung cancer in an unselected Caucasian population. APMIS 2015;123:108-15.

20. Zhuo M, Zheng Q, Zhao J, et al. Survival difference between EGFR Del19 and L858R mutant advanced non-small cell lung cancer patients receiving gefitinib: a propensity score matching analysis. Chin J Cancer Res 2017;29:553-60.

21. Leduc C, Merlio JP, Besse B, et al. Clinical and molecular characteristics of non-small cell lung cancer (NSCLC) harboring EGFR mutation: results of the nationwide French Cooperative Thoracic Intergroup (IFCT) program. Ann Oncol 2017;28:2715-24.

22. Li F, Du X, Zhang H, et al. Next-generation sequencing of Chinese stage IV lung cancer patients reveals an association between EGFR mutation status and survival outcome. Clin Genet 2017;91:488-93. 
23. $\mathrm{Wu} \mathrm{YL}$, Zhou $\mathrm{C}, \mathrm{Hu} \mathrm{CP}$, et al. Afatinib versus cisplatin plus gemcitabine for first-line treatment of Asian patients with advanced non-small-cell lung cancer harbouring EGFR mutations (LUX-Lung 6): an open-label, randomised phase 3 trial. Lancet Oncol 2014;15:213-22.

24. Lin CC, Hsu HH, Sun CT, et al. Chemotherapy response in East Asian non-small cell lung cancer patients harboring wild-type or activating mutation of epidermal growth

Cite this article as: Li B, Ren X, Guo H, Guo Y, Han F, Wen X, Wu J, Li X, Ren Y, Hu X, Liu Z. Prognostic role of epidermal growth factor receptor mutation status in patients with de novo lung adenocarcinoma. Transl Cancer Res 2021;10(3):1549-1558. doi: $10.21037 /$ tcr-21-402 factor receptors. J Thorac Oncol 2010;5:1424-9.

25. Leduc N, Atallah V, Agossou M, et al. Lung Adenocarcinoma Survival in EGFR-Mutated AfricanCaribbean Patients: A Multicenter Study in the French West Indies. Target Oncol 2017;12:689-93.

(English Language Editor: B. Draper) 